\title{
Tecnologia educacional: apoio à representação do professor de Ciência e Tecnologia e instrumento de estudo para o aluno
}

\author{
Maria Isabel Timm* \\ Milton Antonio Zaro** \\ Fernando Schnaid*** \\ Paulo Augusto Cabral**** \\ Roberto Contino Thaddeu*****
}

Resumo: O artigo discute a necessidade de desenvolver, junto aos professores de Ciência e Tecnologia, a capacidade de representação dos conteúdos que ministram, em múltiplas linguagens, apoiadas em diferentes meios de comunicação, ou tecnologias educacionais, sejam elas interativas ou convencionais, como forma de agregar valor ao seu próprio trabalho, qualificando o produto de sua pesquisa. Mesmo que a transmissão de conhecimento não seja considerada como a atividade preponderante do contexto da relação professor-aluno, educadores não devem descuidar do planejamento de elementos destinados a enriquecer a exposição de conteúdos, nos momentos em que isto se fizer necessário, seja em atividades presenciais ou à distância. Necessitam, para tanto, desenvolver habilidades específicas para conhecer e explorar as linguagens e os recursos tecnológicos oferecidos pelos ambientes de produção e disponibilização de multimídia, bem como de mídias convencionais, como as apresentações orais, os livros ou mesmo o quadro (negro, verde ou branco). Além da reflexão sobre a importância de diferentes tecnologias educacionais na atividade docente, bem como no suporte do estudo dos alunos, serão relatadas experiências de produção de três CDs didáticos e de uma série de vídeos destinados, as quais descrevem objetivos, dificuldades e potencialidades desse tipo de mídia.

Palavras-chave: ensino de Ciência e Tecnologia, aulas expositivas, tecnologia educacional.

Abstract: This paper suggests the importance to develop, among teachers in Science and Technology, the content representation skill, in several languages, in different medias, or educational technologies, interactive or conventional they may be, to add more value to teacher's work and to qualify their research results. Even that knowledge transmission has not been considered the most important activity in the context of teacher-student relationship, educators must not forget to plan some elements to improve their lectures, whenever it is needed, both in distant or in face-to-face education. For this, they need to develop specific skills to know and to explore the languages and the technological resources offered by multimedia environments, as well as conventional ones (oral presentation, books, black-white-green boards, etc.). Besides discussion about the importance of different educational technologies, to the teacher's activity and to support students process of learning, this paper presents production process, objectives, problems and potential use of three didactic CDs and a set of educational videos.

Key words: Science and technology education, lectures, educational technology.

\footnotetext{
* Jornalista, Doutoranda PPGIE, Coordenadora Operacional do Núcleo de Multimídia e Educação a Distância da Escola de Engenharia da UFRGS, betatimm@ufrgs.br, www.nmead.ufrgs.br

** Professor, Phd, Coordenador Pedagógico do Núcleo de Multimídia e Educação a Distância da Escola de Engenharia da UFRGS, zaro@ufrgs.br, www.nmead.ufrgs.br

*** Professor, Phd, Coordenador Geral do Núcleo de Multimídia e Educação a Distância da Escola de Engenharia da UFRGS, fernando@ufrgs.br, www.nmead.ufrgs.br

**** Jornalista, Mestrando do Programa de Pós-Graduação em Ciência do Movimento Humano da ESEF, técnico em realização audiovisual do Núcleo de Multimídia e Educação a Distância da Escola de Engenharia da UFRGS, pazcabral@yahoo.com.br

***** Professor, MSc, Chefe do Departamento de Farmacologia UFRGS, farmacologia@ vortex.ufrgs.br
} 


\section{Agregar valor às aulas expositivas}

Na última década, pesquisadores da área da Antropologia sugeriram que as pinturas rupestres tenham sido não apenas um elemento mágico usado por tribos desejosas de se apropriar do poder da caça representada, mas seriam formas de ensinar aos caçadores da tribo qual era a caça a ser buscada e exterminada (Moscov, 1990), fato que, se comprovado, documenta a importância dos instrumentos de representação para a comunicação de idéias, conceitos, práticas e atitudes, sem que isso, em si, minimize a importância da apreensão individual, ativa, de cada um desses ensinamentos, pelos ouvintes-assistentes. Entretanto, não são poucas as considerações que se referem, hoje, na área educacional, à necessidade de desenvolvimento de novos paradigmas centrados em novas posturas do professor, não mais como emissor-comunicador de informações e possíveis conhecimentos, mas como mediador do processo individual dos alunos de construção endógena do conhecimento; organizador das possibilidades do acesso dos alunos ao universo de interesses do assunto em pauta; observador da busca autônoma dos alunos; e, caso seja solicitado, um solícito resolvedor de dúvidas. Moraes (2000) analisa a postura desejável de professores de ciência, ressaltando a necessidade de compromisso com uma postura de permanente auto-construção, usando mesmo os termos incompleto e inacabado, para definir esse novo papel. Bazzo (1998) critica especificamente ao ensino de Engenharia, cuja tradição de exposição de conteúdos herdada do modelo de ensino tecnológico industrial, seria uma das inadequações às demandas educacionais do Seculo XXI.

Identificadas como uma obsoleta tentativa de transmissão pura e simples de conteúdos, as exposições de conteúdos acabaram sendo consideradas, de forma geral e muitas vezes incompleta, como métodos reducionistas e/ou puramente positivistas (Yus, 2002), classificações que, na prática, contribuem para que alguns professores menosprezem as alternativas de torná-las mais eficientes. Um dos objetivos desse trabalho é refletir sobre o fato de que, pelo menos em áreas de alta exigência de domínio de conteúdos técnico-científicos, como é o caso do ensino de Engenharia, ainda é fundamental a necessidade de apresentação de conteúdos, na forma de aulas expositivas, palestras ou seminários, que podem incluir, além de recursos audiovisuais, estratégias de apresentação dialogadas, intercaladas com pesquisas individuais ou em grupo dos alunos.

Aulas expositivas ou atividades semelhantes, de apresentação de conteúdos, são recursos que não podem ser abandonados, nesses cursos, se não como modelo único, pelo menos como partes de modelos pedagógicos comprometidos com qualidade, em cursos presenciais ou à distância ${ }^{1}$. Submeter os alunos, em $100 \%$ de seu tempo de estudo, à construção autônoma do conhecimento, em áreas onde um acervo já foi constituído e estruturado ao longo de séculos de avanço científico e tecnológico, não seria apenas mais lento, como provavelmente inviabilizaria a manutenção de critérios já consagrados de qualidade e confiabilidade de produtos e serviços, critérios estes que são ensinados e aprendidos em cursos dessa natureza e usufruídos por todas as camadas sociais e econômicas, como casas, carros, computadores, construções, instalações elétricas, etc. (Schnaid e outros, 2002).

Como sugere Meirieu (1998), pode-se "fazer com que o outro faça algumas economias de tempo e de meio" (p. 35), através da facilitação do contato dos alunos com os conteúdos estruturados, sem que isso signifique contestar o imperativo de que só há conhecimento quando o aprendiz se apropria dele de forma autônoma, constituindo endogenamente uma estrutura capaz de reconhecê-lo e operar com ele. Nesse sentido, se terá em mente que a recepção de informações orais e visuais não constitui, em si, uma operação cognitiva obrigatoriamente passiva ou estática, uma vez que as operações

\footnotetext{
$2-$ V.2 No2, Novembro, 2004
} 
cognitivas do direcionamento da atenção, identificação de conhecimento prévio e conexões com estruturas mentais já existentes são identificáveis neuro-biologicamente como básicas e funcionais em termos das atividades cognitivas de aquisição, consolidação e evocação de memórias, consideradas como estruturas do conhecimento humano (Del Nero, 1997). Considera-se, entretanto, que a motivação para o direcionamento da atenção do aluno é outro fator importante a ser levado em consideração, contribuindo para ela a forma de acesso ao conteúdo, o ambiente, a afetividade circundante e, inclusive, a necessidade prática que levou o aluno ao conteúdo, seja ela o desejo de ganhar mais, de ganhar nota ou de aprimorar seu conhecimento no tema em pauta.

\section{Planejar recursos audiovisuais é objetivo desejável}

A multiplicação de eventos como palestras, seminários e colóquios, nos quais o apresentador obrigatoriamente deverá apresentar um tema, para debates ao final - um modelo que lembra o modelo didático de aulas expositivas -, dá provas diárias de que as exposições podem ser melhores, piores, mais tediosas, mais participativas, mais dialogadas, mais envolventes da atenção da platéia, situações fortemente influenciadas pela familiaridade do expositor com os recursos tecnológicos que estão à sua disposição, seja sua própria voz, gestos e consciência da sua capacidade narrativa, sejam lâminas, vídeos, animações, etc. Peters (2001) remete à questão da tecnologia educacional e às estratégias de design didático utilizadas para a construção de grandes sistemas de ensino à distância em universidades européias, que desenvolveram processos de planejamento, construção, intervenção, controle e avaliação dos alunos (muitas vezes criticados por sua natureza diretiva), os quais entretanto, segundo o autor, trouxeram vantagens aos planejadores de projetos de grande escala, utilizando, primeiro, os meios de comunicação audiovisuais (rádio e vídeo) e posteriormente os computadores, poderosos auxiliares da capacidade de representação de conteúdos incluída aí a facilidade de visualização de conceitos complexos, bem como a interatividade do retorno sempre que desejado pelo aluno.

Sugere-se que o domínio de recursos de apoio à representação de conteúdos e sua posterior comunicação aos alunos é fundamental ao trabalho do professor, sejam esses recursos sua voz, sua memória, seu raciocínio, seu texto ou o micro-computador, todos ferramentas de representação multifuncional do conhecimento, em sua área de inserção social e profissional. Através dessas ferramentas, o professor vai estruturar seu trabalho em termos de uma continuidade, possivelmente cumulativa, de informações e representações atualizadas de sua área. Os suportes que usar para representar essas informações serão os instrumentos de mediação da comunicação do professor - sujeito de seu próprio trabalho - com alunos (e platéias em geral) de uma turma, e das turmas que se seguirem, cada uma das quais terá 10, 15, 30 ou mais sujeitos de suas próprias recepções daquela comunicação. Esta sugestão, do ponto de vista conceitual, pretende delimitar os contornos de um modelo mais complexo e dinâmico de representação da relação professor-alunos, no qual não há apenas uma único sujeito, em uma fotografia ideal de tempo, mas uma fractal de momentos nos quais os sujeitos, ao interagir, se alternam, alterando - no tempo e no espaço - sua posição no processo de interação, bem como os respectivos pesos de sua maior ou menor atividade preponderante (participação ativa) em cada momento.

$\mathrm{Na}$ prática, sugere-se o resgate da exposição de conteúdos - e seu aperfeiçoamento - como instrumento didático-pedagógico desejável para as áreas do ensino científico e tecnológico, dentro da constituição de modelos pedagógicos flexíveis e dinâmicos, onde este e outros recursos vão constituir ferramentas válidas e eficientes, 
de acordo com o objetivo e a necessidade do aluno, do professor e do próprio conteúdo. É possível que, nesse caso, as aulas expositivas também viabilizem a ação prática e construtiva do aluno, de forma individual e/ou compartilhada, para sua própria construção endógena de conhecimento. Nesses casos, a tecnologia educacional pode contribuir para esse processo, quando destinada a potencializar e facilitar a capacidade de expressão e comunicação do professor, em múltiplas linguagens, em múltiplos suportes, bem como a apoiar a visualização de conceitos abstratos, servir de instrumento de estudo e constituir acervo de pesquisa.

\section{Múltiplas representações para diferentes momentos e funções}

Apenas para efeitos puramente didáticos, suponham-se possíveis categorias de conjuntos de tecnologias: a voz do professor, sua memória e sua expressão gestual, por exemplo, estariam em uma suposta categoria A. Esses mesmos elementos, combinados com o uso de um quatro - branco, negro ou verde - para uso aleatório do professor e/ou dos alunos, sem nenhum tipo de planejamento, formariam a categoria B. Os mesmos elementos da personalidade corporal do professor (voz, gestos, capacidade narrativa, olhar, memória, etc.), associados a um planejamento e habilitação para seu uso, mais uma organização prévia do conteúdo no quadro (com giz colorido usado para ressaltar temas, desenhos feitos à mão, entre outros elementos possíveis de ser representados no quadro), constituiriam uma suposta categoria C. Mesmo intuitivamente, sugere-se que seria lógico prosseguir na descrição da continuidade desse conjunto, propondo que $D$ seria C mais um conjunto de lâminas; e $E$ seria D mais, por exemplo, um banco de mídias (vídeos, fotos, animações, etc.). Insistindo-se que as categorias não representam valor positivo ou negativo - até porque as evidências provam que há professores reconhecidamente talentosos para usar apenas, e bem, sua capacidade pessoal de comunicação - o que se propõe é a tomada de consciência de múltiplas possibilidades de apoio à sua apresentação do conteúdo, cujo uso consciente e eficiente está a serviço do aprendizado do aluno e não contra ele.

Suponha-se, ainda, que, uma vez decompostas as representações em seus múltiplos possíveis elementos pessoais (exposição do professor), escritos (textos), visuais (imagens), dinâmicos (vídeos e animações) ou mesmo sonoros (áudio), fosse possível identificar funções diferenciadas e específicas de cada tecnologia educacional, dependendo do momento em que for usada, do tipo de platéia/turma de alunos, de cada aluno individualmente (estilos ou preferências cognitivas), de sua necessidade, e mesmo do tempo disponível em cada curso. Por exemplo: exposições orais - bem ilustradas seriam usadas para introduzir e delimitar o assunto; vídeos e animações teriam a função de sintetizar de forma visual os conceitos, contribuindo para despertar a curiosidade do aluno; textos e CDs teriam a função de aprofundar e diversificar para temas relacionados, quando o aluno tiver mais tempo disponível.

A integração eficiente entre todos esses elementos deve oferecer um desejável nível de redundância na informação disponibilizada, para aumentar as possibilidades de acesso. Nesse caso, seria possível supor que cada tecnologia não necessita, obrigatoriamente, fazer parte do processo de construção ativa de todos os alunos, ao mesmo tempo, uma vez que cada um irá trabalhar, individualmente, com suas formas prioritárias de representação do conteúdo. Por outro lado, o uso conjunto de múltiplas linguagens (texto, som, imagem) tem condições de resultar em um conjunto de estímulos variados ao aluno, acionando centros de processamento mentais de informações também diferentes, com conseqüências possivelmente benéficas em termos de eficiência na aquisição de conhecimento (Thaddeu, 1997; De Almeida e outros, 1998). 
Suponha-se, finalmente, que existam momentos diversos ao longo das relações educacionais: momento-professor-aluno, momento-aluno-colegas, momento-alunoprofessor, momento-aluno-tecnologias e momento-aluno-sozinho, entre outras possibilidades de interação. Em cada um desses momentos, obrigatoriamente, a questão da representação do conteúdo abordado estará presente, seja de forma estruturada ou coloquial, formal ou informal, metódica ou aleatória, partindo do professor, da tecnologia ou do colega. Sugere-se que seja papel do professor compreender e planejar esta diversidade de tipos de interação, bem como sua dinâmica, de acordo com a necessidade de cada etapa do processo de aprendizagem pretendido e de acordo com o objetivo que estiver estabelecido naquela etapa, segundo as necessidades geradas pelos assuntos específicos que estiverem sendo tratados. Este planejamento pode incluir exposições de conteúdo, pelo próprio professor ou por convidados, tanto quanto pode incluir atividades de pesquisa individual, discussão de grupo ou coletiva, assistência a um vídeo, exploração de um ambiente virtual, de um $\mathrm{CD}$ ou de um livro, em combinações infinitas, segundo objetivos claros para o professor e para o próprio aluno. Talvez com esse tipo de planejamento o professor esteja potencializando sua própria função, enquanto comunicador de conteúdos e valores e enquanto mediador do processo de construção de cada aluno. Esta pode ser uma forma de contribuir para que tome consciência de sua identidade de professor, enquanto sujeito de seu próprio processo de ator social encarregado de constituir culturalmente e cumulativamente um conjunto de saberes, contribuindo para balizar os limites entre os espaços do desenvolvimento de cada aluno e do conjunto, em que ele mesmo se insere (função educacional localizada no escopo da identificação e cumprimento de regras sócio-culturais), e contribuindo também para a validação de conteúdos, valores e compreensões de realidade subjetivas e operacionais que vão garantir, no limite, a integridade dos conceitos, práticas e procedimentos necessários ao bom funcionamento da cultura.

A(s) tecnologia(s) educacional(is) será(serão) apenas a(s) ferramenta(s) de representação da realidade e comunicação dessa representação aos alunos, pelo professor, um profissional cuja função social, dentre outros aspectos, é representar e comunicar conjuntos de conhecimentos de uma geração a outra ${ }^{2}$, introduzir o aluno à cultura de pesquisa, ajudá-lo a aprender a pensar e a adquirir habilidades para aprender sozinho, além de contribuir para transmitir todos os valores da sociedade da qual faz parte. Além disso, através dela(s) o professor vai estabelecer o padrão desejável naquele grupo para abordar o tema proposto, uma exigência de qualidade que, longe de limitar, estende o olhar do aluno em direção a metas possíveis. Qualquer representação vai exercer um impacto nos alunos, coletiva e ou individualmente, sendo desejável, portanto, que esse impacto possa ser, em si, exigente e desafiador, e pode-se imaginar que alunos sintam-se motivados a construir representações compatíveis com as que foram apresentadas pelo professor.

A seguir, serão descritos materiais produzidos pela equipe do Núcleo de Multimídia e Ensino à Distância da Escola de Engenharia e do Programa de PósGraduação em Informática na Educação:

- três CDs realizados no escopo de projeto de produção de material didático, para áreas distintas, embora afins: Engenharia Mecânica (instrumentação, automação e controle, resistência dos materiais, estruturas e ensaios mecânicos), Física (instrumentação, eletromagnetismo, sensores, laboratórios em geral) e Educação Física (biomecânica, cinesiologia, treinamento e atletismo).

- uma série de vídeos didáticos destinados a apoiar aulas de Farmacologia, sobre os Efeitos Farmacológicos no Sistema Nervoso.

\section{CDs didáticos: hipermídia e apoio ao estudo}


Os CDs didáticos foram os primeiros instrumentos a permitir aos professores a integração de forma hipermediática de várias formas de representação, no tempo em que a Internet não oferecia ainda as possibilidades de acesso rápido aos recursos audiovisuais) e já se antecipavam seu potencial de uso no ensino de Ciência e Tecnologia (Zaro e Timm, 2000). Embora o suporte CD tenha se tornado de certa forma obsoleto em termos de volume de dados (um DVD suporta $4.7 \mathrm{~Gb}$ de dados enquanto um CD suporta em torno de $700 \mathrm{Mb}$ ), seu uso ainda continua difundido, inclusive comercialmente (há muitos CDs educacionais à venda, em especial para níveis elementares de educação). Sua grande vantagem é viabilizar o acesso audiovisual instantâneo, de forma hipertextual, em uma mídia cujo acesso - pelo menos por enquanto - ainda é facilitado por fazer parte de uma configuração praticamente universal dos computadores disponíveis no mercado. Além disso, caracterizam uma espécie de conjunto fechado de representação em uma determinada fase do trabalho do professor (como ainda são os livros), o qual, ao contrário de um site na web, não necessita ser pensado em termos de atualização periódica, administração de servidor, acessos, alterações, etc. Sugere-se neste trabalho que a produção de CDs didáticos pode servir como um laboratório de representações audiovisuais para o professor, por permitir a utilização de textos, vídeos, gráficos, animações, softwares, etc., constituindo recurso importante para apoiar a apresentação de conteúdos extensos, abstratos ou muito exigentes, como ocorre nas áreas de Ciência e Tecnologia. Além disso, para o aluno, os CDs constituem um recurso precioso como instrumento de estudo, de acesso permanente, sem limitações de banda ou tempo de conexão.

O primeiro desses CDs - Medições Mecânicas - caracteriza uma atualização de produto cuja primeira versão foi desenvolvida em 1999 (Zaro e Timm, 2000), para uso no curso de Engenharia Mecânica. A presente versão (programada com o software Macromedia Director) recebeu não apenas conteúdos atualizados, direcionados também às áreas de Física e Educação Física, mas foi desenvolvida com ferramentas mais leves e portáveis (Macromedia Flash), como os outros dois CDs: Strain Gages e Biomecânica. A característica principal desses três produtos é a diversidade de temas afins ao tema principal do $\mathrm{CD}$, integrados em uma abordagem multidisciplinar e multimídia dos três assuntos. A grande facilidade do CD - que é a navegação em hipermídia - facilita aos alunos a inter-relação entre temas e abordagens, sejam elas de natureza teórica ou prática (documentação de atividades em vídeos ou animações). Os CDs serão entregues aos alunos, para serem usados como apoio concreto ao estudo, para consultas e resolução de problemas. Além disso, cumprem a função de ilustrar a atividade permanente do professor nestas áreas, seja em aulas expositivas ou em palestras para estudantes, técnicos e empresários ${ }^{3}$. Como os CDs não são complementares, nem sequer fazem parte de uma série, não existe um projeto de design visual comum entre eles. ${ }^{4}$ As figuras a seguir dão exemplo da multiplicidade de abordagens e do tipo de recurso acessível aos alunos.

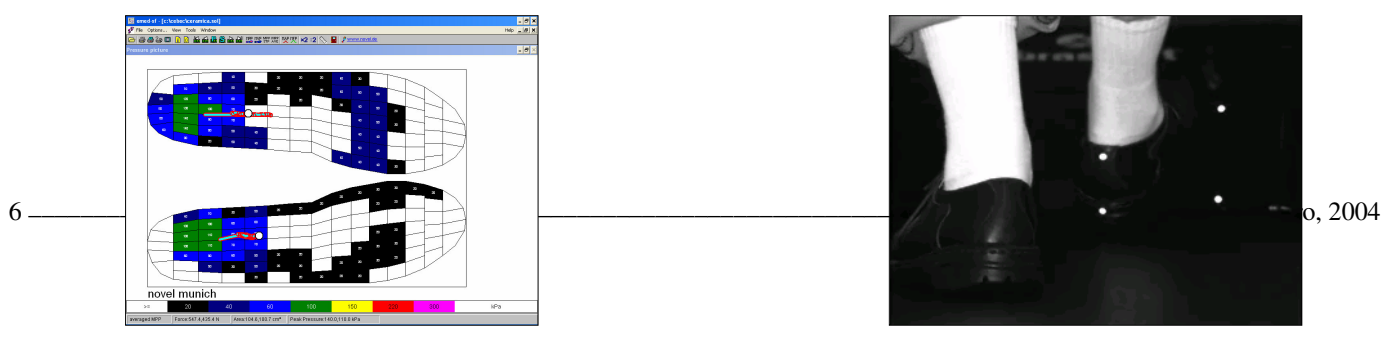


Figura 1 - CD Biomecânica Distribuição da pressão plantar obtida com palmilha eletrônica colocada dentro do calçado

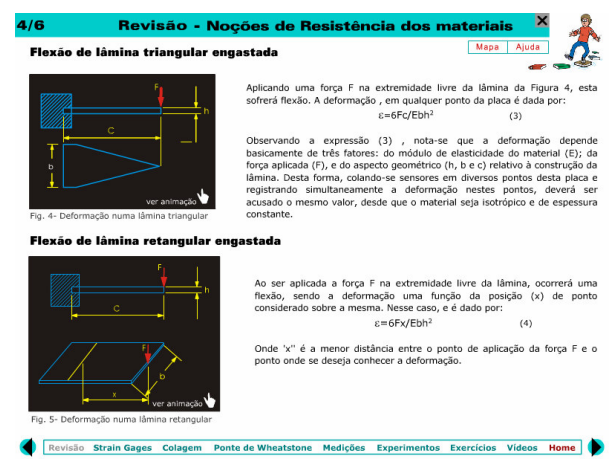

Figura 3 - CD Straing Gages - animações para visualizar o movimento

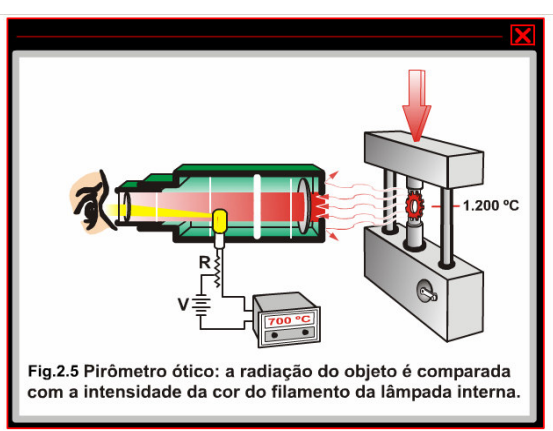

Figura 5 - CD Medição de Temperaturaanimação de funcionamento de equipamento
Figura 2 - CD Biomecânica -

Imagem mostrando pontos reflexivos, que servem de base para análise de movimentos $e$ ângulo - aplicação da Cinemetria

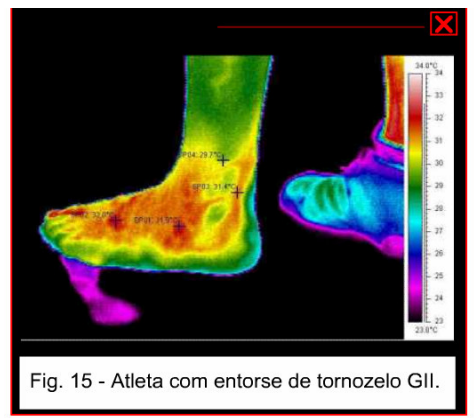

Figura 4 - CD Medição de

Temperatura - visão termográfica de lesões de atletas (inovação em termos

O CD de Strain Gages foi planejado para atender as áreas da Engenharia e da indústria em geral que trabalham com utilização de sensores de deformação, que podem ser a base de transdutores de força (células de carga e plataformas de força), torque, pressão (manômetros), aceleração e deslocamento, dentre outros. Este CD pode ser utilizado também para curso de treinamento de pessoal técnico de indústria, pois, além do conteúdo básico descreve todo o procedimento de colagem, ligação elétrica, projeto e construção de transdutores. Além dos conteúdos presentes no referido $\mathrm{CD}$, também são apresentadas simulações, mostrando dinamicamente o uso desse tipo de sensor, bem como um vídeo que mostra a preparação da superfície e o processo de colagem dos strain gages.

E o CD de Biomecânica destinou-se a apoiar o ensino dessa área, nos cursos de graduação e pós-graduação em Educação Física, com ênfase no uso de tecnologias como a dinamometria, eletromiografia, cinesiologia, antropometria e termografia. É importante salientar que a termografia é uma técnica muito recentemente incorporada à 
área da Biomecânica e que, por esta razão, praticamente não aparece nos livros-textos da área. Neste trabalho são mostradas inúmeras fotos envolvendo imagens termográficas de atletas em treinamento, bem como imagens utilizadas em prevenção e recuperação de lesões. São também mostradas plataformas de força, seu princípio de funcionamento e uso nestas áreas da saúde, mostrando desde absorção de impacto até as componentes de força presentes durante atividade de marcha. Na eletromiografia, destacam-se os eletrodos de superfície e de penetração, o uso, principalmente na avaliação da fadiga muscular, com ênfase no processamento do sinal eletromiográfico.

\section{Vídeos educacionais: visualização e resumo de rotinas}

Com base em trabalhos realizados anteriormente (Schnaid e outros, 2003), foram produzidos em parceria com professores ${ }^{5}$ de Farmacologia do Instituto de Ciências Básicas da Saúde (ICBS) da Universidade Federal do Rio Grande do Sul (UFRGS) uma série de quatro vídeos sobre os Efeitos Farmacológicos no Sistema Nervoso. A estrutura de realização deste trabalho obedeceu aos critérios basicamente estruturados a partir do conteúdo utilizado pelo professor em suas aulas convencionais (lâminas), os quais foram sintetizados em um roteiro, para identificação de possíveis inserções de recursos ilustrativos audiovisuais: vídeo-clipes captados em laboratórios ou em campo; slides com gráficos, tabelas e texto; animações gráficas em 3D, simulando os efeitos dos fármacos no sistema nervoso.

O processo de produção dividiu-se em várias etapas, algumas simultâneas: elaboração do roteiro adaptado (define a necessidade de produção do material de ilustração);

- produção das ilustrações e das lâminas (utilização de recursos de software gráfico: Corell Draw e Power Point);

- produção das animações em 3D(utilização de recursos de software gráfico: 3D Studio);

- gravação em estúdio da apresentação dos professores (professor reproduzindo uma aula baseada no roteiro sintetizado, diretamente para câmera);

- gravação das tomadas em laboratório (a partir de indicações, agendamento e planejamento prévio no local);

- edição final e pós-produção (inserção do material ilustrativo e das tomadas externas ao material gravado no estúdio, inserção de vinhetas de passagem e de trilhas musicais pontuais);

- correção da edição (processo realizado conjuntamente com os professores, para garantir a precisão do conteúdo e das ilustrações).

A locução do professor feita durante a apresentação da aula serve como estrutura-guia para a edição final do material. A imagem e a voz do professor servem como âncora para a narrativa do vídeo, sendo que a imagem é intercalada com as ilustrações. Desta forma buscou-se preservar a espontaneidade característica do professor na apresentação de seus conteúdos em sala de aula, transportando para o vídeo a fluência e a naturalidade de sua performance. Os principais problemas de produção desse tipo de vídeo relacionam-se com a pouca familiaridade dos professores com a linguagem, que acarreta, em primeiro lugar, um desconforto com o ambiente do estúdio e a necessidade de regravação. Em segundo lugar, os tempos de produção (agravados pelas necessidades de regravação e de correção do trabalho) implicam em disponibilidade de tempo do professor, junto à equipe de produção.

Apesar dos problemas de produção, a potencialidade dos vídeos educacionais na apresentação dos conteúdos é notável, tanto pelas razões práticas de apoio ao estudo como por razões éticas, uma vez que reproduzem rotinas de experimentos com animais 
(os quais, com o uso dos vídeos, não necessitam ser sobrecarregados e eventualmente sacrificados para demonstrar técnicas, a cada turma de alunos). Como instrumento de estudo, sua principal característica é a sistematização dos temas, apoiada em elementos visuais que permitem representar dinamicamente o mundo da anatomia e da fisiologia microscópica, como por exemplo, as sinapses e a ação de fármacos na sua inibição ou na excitação. Os vídeos serão disponibilizados na biblioteca, para acesso dos alunos, e também usados para complementar as exposições dos professores da área.

O primeiro vídeo apresentou a anatomia do sistema nervoso central, sendo de especial referência a importância da animação das vias dos neurotransmissores, bem como das sinapses. Foram representadas em 3D (animações): o processo de liberação e a atuação dos neurotransmissores; a auto-regulagem sináptica e a atuação farmacológica nas sinapses.

No segundo vídeo, foi apresentada a metodologia psicofarmacológica na investigação do comportamento, com detalhe gráfico animado da classificação dos tipos de memória (curta e longa duração), com os respectivos circuitos neurais envolvidos em cada uma. Foram gravadas, no laboratório, as técnicas de condicionamento em animais (ratos), e descritas as vias de administração de fármacos: intra-peritonial, intra-cérebroventricular e intra-cerebral (as duas últimas através de cirurgia estereotáxica), procedimentos que, ao vivo, significariam dano às cobaias.

No terceiro vídeo da série foram apresentados efeitos de ansiolíticos, hipnóticos e anti-convulsivantes no sistema nervoso central, tendo sido novamente aí animados os mecanismos de ação desses fármacos, no mundo microscópico da sinapse entre os neurônios, particularmente significativos para apoiar a visualização dos alunos, em área de alta exigência de abstração. O quarto vídeo apresentou uma outra vantagem desse tipo de representação, ao documentar, in loco, cirurgia em pacientes reais, em ambiente hospitalar. Foram filmadas técnicas de anestesia (raquidiana e peridural), para fins de apresentação dos efeitos de anestésicos locais e bloqueadores neuro-musculares. A continuidade do trabalho prevê a disponibilização dos vídeos em banco de dados virtual, para acesso sob demanda dos alunos, além de uso continuado dos professores, visando a melhoria das aulas. Futuramente, é possível que tais recursos sejam utilizados para compor acervos virtuais, em cursos à distância.
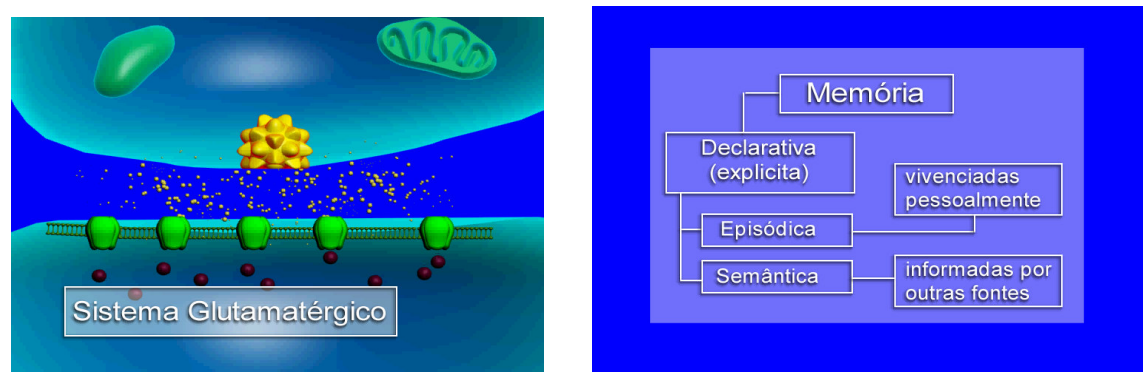

Figura 6 e 7 - Material sobre Vídeos dos Efeitos Farmacológicos

\section{Conclusões}

Os exemplos apresentados contribuem para a reflexão sobre a importância do desenvolvimento de material em múltiplos suportes, para compor acervo à disposição dos alunos, como ferramenta de estudo com múltiplas finalidades, em momentos variados do processo educacional. Além disso, esses materiais contribuem para o estabelecimento de padrões de qualidade na exposição de conteúdos, particularmente 
desejáveis em áreas de ensino de Ciência e Tecnologia, nas quais a prática de aulas expositivas ainda se constitui em ferramenta importante, que pode ser valorizada em benefício do aluno, além de agregar valor ao trabalho do professor.

${ }^{1}$ A idéia de que as aulas expositivas são fundamentais para os modelos pedagógicos, não se constituindo em contraponto a modelos construtivistas, foi enfatizada pelo prof. Fernando Becker, do Programa de Pós-Graduação em Educação da UFRGS, durante workshop virtual realizado em 31/01/2002. Palestra disponível em http://www.nmead.ufrgs.br/nmead/acervo_categoria.asp?id_tipo=1 , que fará parte de um livro a ser publicado.

${ }^{2}$ Essa consideração é reforçada para salientar a opinião dos autores a respeito da importância da função da transmissão de conteúdos pelo professor, a qual, ao longo dos últimos anos, tem estado diluída, além de todas as outras atividades de natureza social e educacional.

${ }^{3} \mathrm{O}$ autor dos CDs é atualmente um dos coordenadores do Núcleo de Multimídia e Ensino à Distância, professor e orientador do Programa de Pós-Graduação em Informática na Educação, professor na Especialização e co-orientador e no Mestrado em Educação Física da UFRGS, professor de Física nos cursos de Engenharia ULBRA e diretor do Laboratório de Conforto de Calçados do Centro Tecnológico do Couro, Calçados e Afins do Rio Grande do Sul.

${ }^{4}$ Não foram usados mais recursos audiovisuais em virtude das dificuldades de custeio de pessoal. Agradece-se ao CNPq o financiamento do projeto.

${ }^{5}$ Professores Roberto Contino Thaddeu, Elaine Elisabetsky, Maria Beatriz Ferreira e Wolney Caumo.

\section{Referências bibliográficas}

BOSCOV, I. Crise ensinou homem pré-histórico a pintar. Folha de São Paulo. São Paulo, 21 dez. 1990. Caderno Ciência. P. G1.

DE ALMEIDA, R.; SOUZA, M.; ROHE, A.; SEFFRIN, R.; GARCIA, C.; THADDEU, R. Interferências intercomportamentais em estudantes: prejuízos da memória por informações da mesma natureza. In: 50. Reunião Anual da SBPC. 1998, Natal. Anais. Sociedade Brasileira para o Progresso da Ciência.

DEL NERO, H.S. O Sítio da Mente. São Paulo: Collegium Cognitio, 1997.

MEIRIEU, P. Aprender...sim, mas como? Porto Alegre: Artmed, 7 ${ }^{\text {a }}$. Edição, 1998.

MORAES, Roque. Construtivismo e Ensino de Ciências: reflexões epistemológicas e metodológicas. Porto Alegre: EDIPUCRGS, 2000.

PETERS, Oto. Didática do Ensino à Distância. São Leopoldo, Brasil: Ed. Unisinos, 2001.

SCHNAID, F.; TIMM, M.I.; ZARO, M.A.; FERREIRA F ${ }^{\circ}$, R.C.M.; CABRAL, P.A.F.; ROSA, M.; JESUS, M. Tecnologia Educacional: mídias e suas linguagens. In: Ciclo de Palestras sobre Novas Tecnologias na Educação. 2003, Porto Alegre. Anais. Universidade Federal do Rio Grande do Sul / CINTED.

SCHNAID, F.; TIMM; M.I.; ZARO, M. Considerações sobre uso de modelo construtivista no ensino de Engenharia: disciplina de projeto com graduandos e mestrandos. Ciclo de Palestras sobre Novas Tecnologias na Educação. 2003, Porto Alegre. Anais. Universidade Federal do Rio Grande do Sul / CINTED.

THADDEU, R.; KESSLER, J.; DE ALMEIDA, R. Prejuízo da memória por interferências intercomportamentais. Dependência da natureza dos processos mentais mobilizados. In: II Congresso Brasileiro de Neuropsicologia. 1997, São Paulo, 1997. YUS, Rafael. Educação integral. Uma educação holística para o Século XXI. Porto Alegre, Brasil: Artmed, 2002.

ZARO, M. e TIMM, M.I. Hipermídia para ensinar e estimular a criatividade: uma experiência pedagógica no LMM - Laboratório de Medições Mecânicas/UFRGS. In: XXVIII Congresso Brasileiro de Ensino de Engenharia. 2000, Ouro Preto. Anais. COBENGE: Congresso Brasileiro de Ensino de Engenharia. 